Vol. 6(8), pp. 252-261, August 2014

DOI: 10.5897/J PHE2013.0634

ISSN 2006-9723

Article Number. 2C 3EF7D46493

Copyright $\odot 2014$

Author(s) retain the copyright of this article

Journal of Public Health and

Epidemiology

http://www.academic joumals.org/JPHE

\title{
Traditional birth attendants and women's health practices: A case study of Patani in Southern Nigeria
}

\author{
Oshonwoh Ferdinand E. ${ }^{2,3 *}$, Nwakwuo Geoffrey $C^{123}$, Ekiyor Christopher P. ${ }^{13}$ \\ ${ }^{1}$ Department of Public Health Technology, Federal University of Technology, P.M.B. 1526, Owerri, Imo State Nigeria. \\ ${ }^{2}$ House of Renaissance for Health Initiative, Warri, Delta State, Nigeria. \\ ${ }^{3}$ RAHI Medical Outreach, Choba Rd, Ozuoba, Port-Harcourt, River State, Nigeria
}

Received 28 February, 2014; Accepted 15 May, 2014

\begin{abstract}
According to the World Health Organization (WHO), current estimate of maternal mortality ratios is at more than 1000 per 100,000 live births in most African countries. Despite the existence of modern health facilities in Nigeria, over $58 \%$ of deliveries take place at home whereas only $37 \%$ take place in hospitals. As outcomes of pregnancy and their sequelae are purely left to the providence of women in many rural communities, the place of delivery is a great determinant of maternal and child morbidity and mortality. With the shortage of skilled birth attendants and uneven geographical distribution of the few available ones; traditional birth attendants tend to fill in the gap. This study employed a cross sectional design and using a simple random sampling technique, 420 women within the reproductive age (18 - 45 years) meeting the inclusion criteria for the study were selected. Results from the study indicated a high (88.8\%) knowledge of Traditional Birth Attendants (TBAs) but a poor (51.1\%) perception about their practices. A significant relationship was shown between age $(P<0.05)$, education status $(P<0.05)$ and the frequency of patronage of TBAs Services. Although, perception about TBAs practices was poor, the role of TBAs in the improvement of women's health (maternal and child health) in rural Nigeria cannot be ignored. TBAs remain major health resources in rural communities in developing countries as well as some parts of urban areas. Efforts need to be harnessed for training of TBAs through the Ministry of Health and Primary Health Care facilities close to their area of practices.
\end{abstract}

Key words: Knowledge, perception, traditional birth attendants, maternal mortality, Southern Nigeria.

\section{INTRODUCTION}

According to the World Health Organization (WHO), the current estimate of maternal mortality ratios is more than 1000 per 100,000 live births in most African countries (WHO, 2005). In developing countries, specifically in Sub-Saharan African, many women do not have access to skilled personnel during childbirth (WHO, 2005). The lack of skilled attendants is one of the major factors responsible for the rising maternal and infant mortality (WHO, 2005). Pregnancy and the events surrounding it are generally viewed as feminine issues exclusively for women and the outcome of pregnancies and their sequelae are purely left to the providence of these

*Corresponding author. E-mail: oshoferd@gmail.com. Tel:+2348138016054.

Author(s) agree that this artic le rema in permanently open access under the terms of the $\underline{C}$ reative Commons Attribution License 4.0 Intemational License 
women especially in many rural communities (Nwakwuo, and Oshonwoh, 2013). Nigeria, a country with more than 160 million people has about $70 \%$ of its population residing in the rural areas. These areas lack the basic amenities of life; good road networks, portable drinking water, and adequate health facilities. The inadequacy of health care facilities and services propagates the existence of Traditional Birth Attendants (TBAs).

Despite the existence of modern health facilities in Nigeria, over $58 \%$ of deliveries still take place at home whereas only $37 \%$ take place in hospitals (United Nations Children's Fund, 2001). It is estimated that between 60 to $80 \%$ of all deliveries in developing countries occur outside modern health care facilities, with a significant proportion of these attended by TBAs (Tsui et al., 1996). TBAs deliver the majority of women in Nigeria as in other developing countries (Tsui et al., 1996). An Eastern Nigerian study showed that although $93 \%$ of rural women registered for prenatal care, $49 \%$ delivered at home under the care of TBAs (Imogie, 2000).

Similarly, a study of 377 women who delivered before arrival at the hospital in Ogbomosho, South-Western Nigeria revealed that $65 \%$ of the mothers had been delivered by a TBA, while $73.7 \%$ had sought help from them for retained placenta with bleeding (Fajemilehin, 1991). In Chanchaga LGA of Niger State in North-Central Nigeria, $84 \%$ of households interviewed utilized the services of a TBA or village health worker (Itina, 1997).

The place of delivery is one of the determinants of maternal and child morbidity and mortality. With shortage of skilled birth attendants particularly, who are also unevenly distributed geographically (United Nations Children's Fund, 2001), Traditional Birth Attendants tend to fill in the gap (Inem et al., 2008). Traditional birth attendants have also been shown to exist in urban areas (Itina, 1997).

Statistics have shown that approximately 630,000 maternal deaths occur annually of which over $99 \%$ occurred in low and middle income countries (Ronsmans and Graham, 2006; Lawn et al., 2005; Martines et al., 2005), mostly Sub-Saharan Africa. Over half of these deaths occur at home without skilled care (Lawn et al., 2005; Martines et al., 2005) and are shown to concentrate around labour, delivery and the immediate post partum period. It suffice to note that up to two-thirds of these deaths are preventable with low-cost, low-tech community based interventions which extends pregnancy through childbirth and could be handled by community health workers (Martines et al., 2005; Darmstadt et al., 2005). Skilled personnel plus an enabling environment to provide essential obstetrics and neonatal care are necessary to achieve a significant reduction in maternal and infant mortality (Ebuehi and Akintujoye, 2012).

Maternal mortality rate in Nigeria is estimated to be approximately 630 deaths $/ 100,000$ live births in 2010; and the main causes identified include; haemorrhage, infection, obstructed labour and hypertension (Khan et al., 2006). Nigeria accounts for $40 \%$ of the global burden of vesico-vaginal fistula, which translates to an estimated 800,000 women suffering from a condition arising from prolonged labour and complicated deliveries.

Access in its various dimensions is a critical determinant of maternal mortality. These dimensions include; physical access, cost, cultural factors and appropriate information which are significant in attaining good maternal indices (Ahmed et al., 2007).

The impact of TBAs practice on maternal outcomes remains inconclusive for years. Efforts to formalize the role of TBAs in maternal and neonatal health programs have had limited success. TBAs continued attendance at home deliveries suggests, however, their potential in influencing maternal and neonatal outcomes (Imogie et al., 2002; Falle et al., 2009). Although, the assumption that training of TBAs would contribute greatly to reduce maternal mortality has been disproved in recent years (World Bank, 2003), interventions to prevent maternal deaths are more or less complex and many are feasible for a wide range of community health workers (Campbell and Graham, 2006) and also the TBAs.

In recent years, there has been increasing debate over the usefulness of TBAs in maternal health care (Sibley and Sipe, 2011). Opponents of TBA care are of the view that TBAs have done little to improve maternal health. They opine that TBAs have frustrated laudable efforts made by governments in Sub-Saharan Africa to reduce maternal mortality, while proponents have expressed the need for a sustained partnership with TBAs as a strategy to improve access to basic maternity care in rural areas to achieve significant reductions in maternal mortality (Ebuehi and Akintujoye, 2012).

Despite the World Health Organization's recommendation for skilled attendance at delivery excludes TBAs (WHO, 2004a), some studies have shown the role of TBAs in improving the health outcomes of mothers and newborns. About $30 \%(95 \% \mathrm{Cl}: 18$ to $41 \%)$ significant reduction in perinatal mortality and $29 \%(95 \% \mathrm{Cl}: 17$ to $43 \%)$ reduction in neonatal mortality in a cluster randomized trial conducted in Pakistan was associated with TBAs practice (Jokhio et al., 2005). Additional studies have shown reduction in the incidence of postpartum complications (Bailey et al., 2002) and increased referral to health facilities (Eades et al., 1993; Akpala, 1994; Ahmed et al., 2007) with TBAs interventions. Also, a study carried out in India on TBAs training in the management of pneumonia was shown to reduce neonatal pneumonia by $44 \%$ (Bang et al., 1994). This is contrary to the joint declaration of WHO/UNFPA/UNICEF that 'Training of TBAs alone, in the absence of back-up from a functioning referral system and support from professionally trained health workers is not effective in reducing maternal mortality" and the assertion that "there is no evidence that such training of TBAs alone leads to reductions in maternal mortality. Although TBAs can provide culturally appropriate nurturing in the community 
Table 1. Socio-demographic characteristics of respondents.

\begin{tabular}{lcc}
\hline Variable & Frequency & Percentage (\%) \\
\hline Age group (years) & 80 & \\
$15-19$ & 56 & 19.0 \\
$20-24$ & 142 & 13.3. \\
$25-29$ & 84 & 33.8 \\
$30-34$ & 58 & 20.0 \\
Above 35 & Mean $26.8 \pm 1.29$ & 13.8 \\
& & \\
Marital status & & \\
Single & 46 & 11.0 \\
Married & 256 & 61.0 \\
Divorced & 28 & 6.7 \\
Separated & 17 & 4.0 \\
Widowed & 73 & 17.4 \\
& & \\
Educational status & & \\
No formal education & 39 & 9.3 \\
Primary & 121 & 28.8 \\
Secondary & 186 & 44.3 \\
Tertiary & 74 & 17.6 \\
& & \\
Religion & & \\
Christianity & 245 & 58.3 \\
Islam & 17 & 4.0 \\
Traditional & 97 & 14.5 \\
Others & 61 & \\
\hline
\end{tabular}

$\mathrm{N}=420$

setting, offer a first-line link with the formal healthcare system and provide some simple services such as the distribution of nutrition supplements" (World Health Organization, 1999).

Despite, there is few evidence of the practice of TBAs in urban areas, their roles in rural community health especially in developing nations can never be over emphasized. With the rising patronage of TBA services by pregnant women who also utilize modern maternity services (Ebuehi and Akintujoye, 2012), there is need to train, incorporate and equip TBAs with necessary assistance to practice and improve maternal and child health. This study intends to ascertain the knowledge and perception of TBAs' practices by women of child-bearing age in Southern Nigeria.

\section{MATERIALS AND METHODS}

The study was carried out in Patani, in the South-South part of Nigeria using a cross-sectional descriptive design. A simple random sampling technique was used to select 420 women within the reproductive age (18 - 45 years) from the study population living in the area, for more than 12 months. Responses were collected using a structured questionnaire distributed to selected respondents at the community, primary health care centres and the General Hospital. Permission was taken from the hospital's ethical committee before the study was conducted in the health facility and questionnaires distributed to patients attending health care services in the hospital. Also consent was sorted from the community leader and women leader to reach out to women in the community.

Focal group discussions and key informant interviews were held with selected TBAs to ascertain the depth of their knowledge as it relates to pregnancy, labour, delivery and complications arising thereof. It was also used to evaluate their level of training and preparedness to recognize danger signs, manage them and ensuring appropriate referral in case of complications for both mother and child before and during delivery and after birth. The discussion was conducted in English, precisely "Pidgin English" and the local language for easy understanding of the TBAs.

Data collected were sorted based on responses, collated and then analyzed using SPSS version 20. Quantitative data were presented in tables. Chi-square and Fisher's exact were used to establish relationships between variables and make inferential conclusion and necessary suggestions.

\section{RESULTS}

Table 1, shows the age groups of the respondents and the most represented age group of the respondents was $25-29$ years $(33.8 \%)$, followed by $30-34$ years $(20 \%)$ and 
Table 2. Knowledge and use of services by Traditional Birth Attendants (TBAs).

\begin{tabular}{lcc}
\hline Variable & Frequency & Percentage (\%) \\
\hline Have you heard of TBAs & 373 & 88.8 \\
Yes & 47 & 11.2 \\
No & & \\
& 147 & 35.0 \\
Do you use the services of the TBAs & 273 & 65.0 \\
Yes & & \\
No & & \\
& 53 & 12.6 \\
How often the services of TBAs is used & 94 & 22.4 \\
Always & 273 & 65.0 \\
Not often & & \\
Not at all &
\end{tabular}

15 - 19 years $(19 \%)$ with a mean age of $29.6 \pm 1.29$. Majority of the women (256) were married 73 were widowed and 46 separated from their family. About $44.3 \%$ of the respondents had secondary education with only $17.6 \%$ attaining the tertiary education level. $58.3 \%$ of the respondents were Christians. $4.0 \%$ were Muslims and $23.1 \%$ are practicing African traditional religion.

Table 2 shows the responses on whether the respondents have heard of Traditional Birth Attendants (TBAs) and aware of or use their services. It shows that, majority (373) accepted to having prior information about TBAs but only 147 of the respondents agreed to having used the services of the TBAs of which 94 do not use the services often and 53 often patronize them.

Table 3 indicates that about $96.4 \%$ of the participants agreed that the services of the TBAs are not expensive but only $34.5 \%$ patronize them because their services are cheap whereas $30.5 \%$ said that they patronize them because there are no alternatives. About $91.4 \%$ agreed that TBAs are located or more common in villages (rural area) than in urban areas. It also shows that $73.1 \%$ of the TBAs use facilities located in their area of practices but only $30 \%$ of these facilities are said to be standard. Although only $8.8 \%$ indicated that TBAs have the required training and skill to practice, $22.1 \%$ of the services provided are up to required standard, majority (83.8\%) of the provided services are mostly unhygienic. Only 4\% used any form of personal protective devices or equipments in the course of their duties.

Despite the contributions of TBAs to community healthcare practices as first point of call for deliveries, about $60.7 \%$ of their services are still shown to be ineffective, with only a few $(60 ; 14.3 \%)$ still wanting the TBAs to continue providing their services to women whereas majority $(310 ; 73.8 \%)$ of the respondents indicated that the TBAs should be trained and assisted to help equip them with reliable skills to perform to expectation and standards.
Table 4 shows the perception of TBAs management practices and about $63.1 \%$ of the TBAs were shown to be helpful to pregnant women with majority coping with likely birth injuries $(26.4 \%)$ and complications but only few render prenatal care $(5.7 \%)$ and family planning services $(2.4 \%)$ to their client/patient while only $45.7 \%$ of complicated cases are referred to hospitals for proper management. Table 5 shows a poor perception (58.1\%) of TBAs' services by women of child-bearing age despite patronage by about $35 \%$ of the respondent as well as high awareness (88.8\%) about TBAs services.

Table 6 shows a significant relationship $(P<0.05)$ between age and the frequency of usage or patronage of TBAs services. Older women (above 35 year) are more likely to use their services more often. It also indicates a significant relationship $(P<0.05)$ between education and frequency of usage of TBAs' services. The more educated the woman the more likely she would not use the services at all. Those with no formal education or with only a primary education are more likely to use the services often.

Table 7 shows no significant relationship $\left(x^{2}=1.177\right.$, $P<0.05)$ between the skill of the TBAs and their ability to cope with birth complications and indicated that only few of the skilled TBAs can cope with birth complications. From the focal group discussion, it was discovered that the TBAs, although less equipped to handle serious complications of pregnancy and childbirth, are willing to undertake any necessary training if provided to them. According to a TBA

"The government is not ready to train us as they think it is a waste of resources. They prefer training their workers but still want to control our practice. This will be difficult because asides from being our source of living, some of us inherited these practices from our parents".

An elderly and popular TBA in the area also has this to 
Table 3. Women's perception of Traditional Birth Attendants (TBAs) practice.

\begin{tabular}{|c|c|c|}
\hline Variable & Frequency & Percentage (\%) \\
\hline \multicolumn{3}{|c|}{ TBA services is expensive } \\
\hline Yes & 165 & 39.3 \\
\hline No & 255 & 60.7 \\
\hline \multicolumn{3}{|c|}{ TBAs patronized because its cheap } \\
\hline Yes & 345 & 82.1 \\
\hline No & 75 & 17.9 \\
\hline \multicolumn{3}{|c|}{ Patronized because of no alternatives } \\
\hline Yes & 245 & 58.3 \\
\hline No. & 175 & 41.7 \\
\hline \multicolumn{3}{|c|}{ TBAs exist in rural area } \\
\hline Yes & 384 & 91.4 \\
\hline No. & 36 & 8.6 \\
\hline \multicolumn{3}{|c|}{ TBA use facilities } \\
\hline Yes & 307 & 73.1 \\
\hline No & 113 & 26.9 \\
\hline \multicolumn{3}{|c|}{ TBAs use standard facilities } \\
\hline Yes & 126 & 30.0 \\
\hline No & 294 & 70.0 \\
\hline \multicolumn{3}{|c|}{ TBAs are skilled } \\
\hline Yes & 37 & 8.8 \\
\hline No. & 383 & 91.2 \\
\hline \multicolumn{3}{|c|}{ TBAs services are standard } \\
\hline Yes & 93 & 22.1 \\
\hline No. & 327 & 77.9 \\
\hline \multicolumn{3}{|c|}{ TBAs services are Hygienic } \\
\hline Yes & 68 & 16.2 \\
\hline No. & 352 & 83.8 \\
\hline \multicolumn{3}{|c|}{ TBAs uses PPE } \\
\hline Yes & 17 & 4.0 \\
\hline No. & 403 & 96.0 \\
\hline \multicolumn{3}{|c|}{ TBAs services are effective } \\
\hline Yes & 165 & 39.3 \\
\hline No. & 255 & 60.7 \\
\hline \multicolumn{3}{|c|}{ TBAs should be trained and assisted } \\
\hline Yes & 310 & 73.8 \\
\hline No. & 110 & 26.2 \\
\hline \multicolumn{3}{|c|}{ TBAs should continue to offer service } \\
\hline Yes & 60 & 14.3 \\
\hline No. & 360 & 85.7 \\
\hline
\end{tabular}


Table 4. Women' perception of management practice of Traditional Birth Attendants (TBAs).

\begin{tabular}{|c|c|c|}
\hline Variable & Frequency & Percentage (\%) \\
\hline \multicolumn{3}{|c|}{ Helpful to pregnant women } \\
\hline Yes & 265 & 63.1 \\
\hline No & 155 & 36.9 \\
\hline \multicolumn{3}{|c|}{ Cope with birth injuries } \\
\hline Yes & 111 & 26.4 \\
\hline No & 309 & 73.6 \\
\hline \multicolumn{3}{|c|}{ TBAs render parental services } \\
\hline Yes & 24 & 5.7 \\
\hline No. & 396 & 94.3 \\
\hline \multicolumn{3}{|c|}{ Offers abortion services } \\
\hline Yes & 111 & 26.4 \\
\hline No. & 309 & 73.6 \\
\hline \multicolumn{3}{|c|}{ Recognizes birth complication } \\
\hline Yes & 376 & 89.5 \\
\hline No. & 44 & 10.5 \\
\hline \multicolumn{3}{|c|}{ Case referral } \\
\hline Yes & 192 & 45.7 \\
\hline No. & 228 & 54.3 \\
\hline \multicolumn{3}{|c|}{ Uses Spiritism } \\
\hline Yes & 37 & 8.8 \\
\hline No. & 383 & 91.2 \\
\hline \multicolumn{3}{|c|}{ TBAs involves in drug description } \\
\hline Yes & 30 & 7.1 \\
\hline No & 390 & 92.9 \\
\hline \multicolumn{3}{|c|}{ TBAs offer family planning services } \\
\hline Yes & 10 & 2.4 \\
\hline No. & 410 & 97.6 \\
\hline \multicolumn{3}{|c|}{ Intend to continue using services } \\
\hline Yes & 49 & 11.7 \\
\hline No. & 371 & 88.3 \\
\hline
\end{tabular}

Table 5. Level of perception of TBAs by women of child bearing age.

\begin{tabular}{lcc}
\hline Classification of Level of perception & Ranking/scores (points) & Frequency (\%) \\
\hline Very good & $\geq 6$ & $37(8.8)$ \\
Good & 5 & $66(15.7)$ \\
Fair & 4 & $73(17.4)$ \\
Poor & $\leq 3$ & $244(58.1)$ \\
\hline
\end{tabular}


Table 6. Age of respondents and frequency of usage.

\begin{tabular}{|c|c|c|c|c|}
\hline \multirow{3}{*}{ Variable } & \multicolumn{4}{|c|}{ Frequency of usage } \\
\hline & \multicolumn{4}{|c|}{ Frequency (\%) } \\
\hline & Often & Not often & Not at all & Total \\
\hline \multicolumn{5}{|l|}{ Age of respondents } \\
\hline $15-19$ & $4(5.0)$ & $51(63.8)$ & $25(31.2)$ & 80 \\
\hline $20-24$ & $6(10.7)$ & $0(0.0)$ & $50(89.3)$ & 56 \\
\hline $25-29$ & $18(12.7)$ & $7(4.9)$ & $117(82.4)$ & 142 \\
\hline $30-34$ & $6(7.1)$ & $16(19.1)$ & $62(73.8)$ & 84 \\
\hline \multirow[t]{2}{*}{ Above 35} & $19(32.8)$ & $20(34.5)$ & $19(32.8)$ & 58 \\
\hline & \multicolumn{4}{|c|}{$\chi^{2}=157.711, \mathrm{df}=8 ; \mathrm{p}$ value $=0.000$} \\
\hline \multicolumn{5}{|l|}{ Educational status } \\
\hline No formal education & $39(100)$ & $0(0.0)$ & $0(0.0)$ & 39 \\
\hline Primary & $14(11.6)$ & $89(73.6)$ & $18(14.8)$ & 121 \\
\hline Secondary & $0(0.0)$ & $5(2.7)$ & $181(97.3)$ & 186 \\
\hline \multirow[t]{2}{*}{ Tertiary } & $0(0.0)$ & $0(0.0)$ & $74(100)$ & 74 \\
\hline & \multicolumn{4}{|c|}{$\chi^{2}=331.262, \mathrm{df}=3 ; \mathrm{p}$ value $=0.000$} \\
\hline
\end{tabular}

$\mathrm{N}=420$.

Table 7. TBAs' skills and coping with birth complication.

\begin{tabular}{lccc}
\hline \multirow{2}{*}{ Variable } & \multicolumn{3}{c}{ Coping with birth complications } \\
\cline { 2 - 4 } & \multicolumn{3}{c}{ Frequency (\%) } \\
\cline { 2 - 4 } & Yes & No & Total \\
\hline TBAs are skilled & $7(18.9)$ & $30(81.1)$ & 37 \\
Yes & $104(27.2)$ & $279(72.8)$ & 383 \\
No & $309(73.6)$ & $111(26.4)$ & 420 \\
Total & & & \\
\hline
\end{tabular}

$\mathrm{N}=420, \mathrm{X}^{2}=1.177, \mathrm{df}=1, \mathrm{p}$-value $=0.278$.

say:

I don't know what this hospital staff feels like, moreover, they don't do the job more than us and yet, they treat us like dirt.

This confirms the tip from a key informant that TBAs and health workers in the clinics and health centres are "cat and dog' that is, not in terms with each other due to the assertion that TBAs complicate issues and leave the trouble of management to them.

\section{DISCUSSION}

The contribution of traditional birth attendants in the improvement of maternal and child health especially in the rural areas cannot be underrated. Traditional birth attendants have remained one of the alternative health resources for women of child bearing age in Patani Local Government Area and most local communities in Nigeria.

Although, $88.8 \%$ of the respondents are actually aware of the services of TBAs, only few (39.3\%) of the users and non-use are convinced of the opinion that the measures used by TBAs are effective. This resulted to poor perception (58.1\%) on the practices of TBAs on improving maternal and child health by women of childbearing age. Reasons have been advanced by the focus group discussion (FGD) as to why some women still default attending maternity clinics for antenatal, perinatal and postnatal services. To some of them, cultural affinity remains as one of the stronghold of why people will continue to patronize TBAs.

Other reasons may include the high and "illegal" hospital fees, the distance of the hospitals and maternity homes to the people, lack of good roads and lack of qualified personnel in such public facilities as well as truancy/inability of some health personnel relocated to 
local communities to settle there. These views are in line with the study carried out by Stock (1983), who in a similar group (FGD) revealed that rudeness of staff, persistence shortage of drugs and time wastage were found to be responsible for the non-utilization of health services.

In another study, it was noted that some of the inhibiting factors to usage of modern health services include prohibitive hospital fees, illegal fee and bribes, lack of drugs and essential supplies, negative staff attitude among others (Martey et al., 1998). According to Okafor and Rizzuto (1994) superstition and misinformation among practicing TBAs has dramatically increased maternal morbidity in the rural areas but from this study, only $8.8 \%$ of such superstition have been shown to still exist in the study area.

Nigeria is a nation with a population of over 160 million with the majority living in the rural area. Despite the existence of modern health facilities in Nigeria, over $58 \%$ of deliveries take place at home whereas only $37 \%$ take place in hospitals (United Nations Children's Fund, 2001). With inadequate facilities and lack of skilled attendants, Traditional Birth Attendants tend to fill in the gap in the delivery of health care services locally (Inem et al., 2008).

TBAs services are not only common in rural areas. Traditional birth attendants have also been shown to exist in urban areas (Itina, 1997) and according to this study, $8.6 \%$ though very few of TBAs services still exist in urban areas. However, it has been observed that the war being waged between trado-medical practitioners and orthodox medical professionals remains unabated as the TBAs are known to suffer a lot of disrespect from local health officials in rural areas and could be worse in urban settings (Owigar, 2000).

In rural areas, health care system is poorly orthodox and some people due to socioeconomic, educational level and poor relationship with health care facilitators prefer to patronize the services of the Traditional Birth Attendants (TBAs). A significant relationship was shown between educational status of the respondents and the frequency of patronage (use) of the services of TBAs $(P<0.05)$. Those with no formal education use the services more often than their counterparts.

There exist people who would not for cultural and ethnographic reasons go to TBAs to have their babies. This might be an indication that the facilities used by TBAs are not standard $(70 \%)$, and the need for training and development of the practices since there are women $(14.3 \%)$ who still wish to continue using the services of the TBAs.

The training of TBAs has been associated with moderate-to-large improvement in their behaviour to postnatal practices and small but significant decrease in perinatal mortality and neonatal mortality due to birth complications such as asphyxia and pneumonia (Sibley and Sipe, 2006).

Although, this study showed no relationship between the skill of the TBAs and their ability to cope with birth complication $\left(x^{2}=1.177, p>0.05\right)$, the weak relationship could be an indication that more requisite training and skills are required by the TBAs to tackle more critical problems or a referral made for proper management. However, due to incomplete data reporting and recording, there have been poor database for association between the training of TBAs and the effectiveness of the services provided.

Throughout history, TBAs have been the main human resource for women during childbirth. Their role varies across cultures and times however, today they attend to the majority of deliveries in rural areas of developing countries (Bergström and Goodburn, 2001; Jemal et al., 2010). There is little doubt that they have a significant role when it comes to cultural competence, consolation, empathy and psychosocial support at birth, all of which are important benefits for the mother and also for the newborn child. Despite WHO recommendation for skilled attendants during delivery excluded TBAs, it observed that TBAs can potentially improve maternal and newborn health at community level. While the role of TBAs in caring for pregnant women and conducting deliveries is acknowledged, it is noted that they are generally not trained to deal with complications (WHO, 2004b). TBAs and village midwives have been employed in many interventions to reduce maternal mortality and improve pregnancy outcomes in developing countries with mixed results (Gloyd et al., 2001; Ray and Salihu, 2004).

According to the result of this study, about $63.1 \%$ of the TBAs have been shown to be of assistance to pregnant women. In another study, 57 traditional birth attendants were identified by the Danfa Project in Ghana in an effort to improve maternal and child health practice and promote family planning (Ampofo et al., 1977).

Owigar noted that to help reduce the maternal mortality rate; there is need for purposeful utilization of the wealth of experience of traditional birth attendants in the efforts to complement the good health status of the women during prenatal, ante- and post-natal services (Owigar, $2000)$. However, from this study only $8.8 \%$ of the TBAs in this study had the required skilled training and Akpala (1994) disclosed in a study on the evaluation of the knowledge and practices of trained TBAs in Bodinga, Sokoto State of Nigeria that out of 74 TBAs, only 43 trained ones where able to recognize high risk pregnancies and deliveries for referrals to higher health institutions than the 31 untrained TBAs.

Therefore to help improve maternal heath especially in the rural areas of Nigeria, something has to be done in areas where TBAs are lacking adequate facilities and training. Although, the wealth of experiences of TBAs have been acknowledged (Owigar, 2000), there is need to encourage them through training and support because TBAs are very much in short supply of standard facilities and mostly compelled to use what they have available which from this study $70 \%$ are known to be substandard to offer the required services. 


\section{Conclusion}

The perception and knowledge of women of child-bearing age on the role of Traditional Birth Attendants (TBAs) in the improvement of women health (Maternal and child health) in Nigeria according to this study is poor but TBAs remain a major health resources in rural communities in developing countries. Previous study recognized that training and providing materials to local village midwives (Geurts, 1997) resulted in the reduction in the incidence of postpartum complications (Bailey et al., 2002), and showed increased referral to health facilities (Eades et al., 1993; Akpala, 1994; Ahmed et al., 2007) with TBAs interventions. The knowledge and practice of traditional birth attendants need to be addressed by policy makers and planners and a positive effort made through research, based on a firm understanding of what TBAs can and cannot do (Imogie, 2011). This will help fathom their strengths and limitations and develop baseline for their training and retraining.

\section{RECOMMENDATION}

Finally, from the findings of this study, the following recommendations have been made toward improving the knowledge and practice of the TBAs:

1. TBAs should be supported both financially and materially by equipping them with the necessities for their practice;

2. Their operations should be recognized and record keeping for both birth and mortality encouraged;

3. Policy to limit the extent of the service and practice will help phase out untrained and inexperienced practices rather than not recognizing the essence of TBAs especially in rural communities;

4. The co-existence of orthodox and transitional maternal and child care services should be encouraged as to create avenue for proper referral of complicated and critical problems;

5. Non-Governmental Organizations involved in primary health care services should be encouraged to get involved in the education and training of TBAs.

\section{ACKNOWLEDGEMENTS}

The authors are gracious to the management and staff of Patani General Hospital and to all participants for their understanding and compliance. My thanks also go to House of Renaissance for Health Initiative for their support for grassroots health development.

\section{Conflict of Interests}

There is no conflict of interest declared.

\section{REFERENCES}

Ahmed ASMNU, Saha SK, Azad Chowdhury MAK, Law PA, Black RE, Santosham M, Darmstadt GL (2007). Acceptability of oil massage with skin barrier enhancing emollients in young neonates in Bangladesh. J. Health Popul. Nutr. 25(2):236-240.

Akpala CO (1994). An evaluation of the knowledge and practices of trained traditional birth attendants in Bodinga, Sokoto State, Nigeria J.Trop. Med. Hyg. 97(1):46-50.

Ampofo DA, Nicholas DD, Amonoo-Acquab MB, Ofosu- Amiah S, Nuemann AK (1977). The training of traditional birth attendants in Ghana: experience of the Danfa Rural Health Project. Trop. Geogr. Med. 29(2):197-203.

Bailey PE, Szaszdi JA, Glover L (2002). Obstetric complication: does training traditional birth attendants make a difference? Pan. Am. J. Public Health 11(1):15-23

Bang AT, Bang RA, Sontakke PG (1994). Management of childhood pneumonia by tradition birth attendants. The SEARCH team. Bull. World Health organization 72(6):897-905.

Bergström S, Goodburn E (2001). The role of traditional birth attendants in the reduction of maternal mortality. Stud. HSO\&P. 17:85-89.

Campbell OM, Graham WJ (2006). Strategies for reducing maternal mortality: getting on with what works. Lancet 368(9543):1284-1299.

Darmstadt GL, Bhutta ZA, Cousens S, Adam T, Walker N, de Bernis L (2005). Evidence-based cost-effective interventions. How many newborn babies can we save? Lancet 365(9463):977-988.

Eades CA, Brace C, Osei L, LaGuardia KD (1993). Traditional Birth attendants and maternity in Ghana. Soc. Sci. Med. 36(11):15031507.

Ebuehi Olufunke M, Akintujoye IA (2012). Perception and utilization of traditional birth attendants by pregnant women attending primary health care clinics in a rural Local Government Area in Ogun State, Nigeria. Int. J. Women's Health 4:25-34.

Fajemilehin RB (1991). Factors influencing high rate of "born-beforearrival' babies in Nigeria - a case control study in Ogbomosho. Int. J. Nurs. Stud. 28(1):13-18.

Falle TY, Mullany LC, Thatte N, Khatry SK, LeClerq SC, Darmstadt GL, Katz J, Tielsch JM (2009). Potential role of traditional birth attendants in neonatal healthcare in rural southern Nepal. J. Health Popul. Nutr. 27(1):53-61.

Geurts KL (1997). Well-Being and Rural Ghana: Local realities and Global Mandates. A paper presented at the Fifth Annual Penn African Studies Workshop.

Gloyd S, Florano F, Seunda M, Chadreque MA, Nyangezi JM, Platas A (2001). Impact of traditional birth attendant training in Mozambique: a controlled study. J. Midwifery Womens Health 46:210-216.

Imogie AO (2011). The Practice of Traditional Birth Attendants and Women's Health in Nigeria. $25^{\text {th }}$ Congress of Medical Women's International Association. The Regional Institute Ltd. Available at http://www.regional.org.au/au/mwia/papers/full/28_imogie.html, (accessed 18.07.13).

Imogie AO, Agwubike EO, Aluko K (2002). Assessing the role of traditional birth attendants (TBAs) in health care delivery in Edo State, Nigeria. Afr. J. Reprod. Health 6(2):94-100.

Imogie OI (2000). The practice of traditional birth attendants and women's health in Nigeria. 25th Congress Medical Women's International Association; (Accessed January 16, 2013). Available from: http://www.regional.org.au/au/mwia/papers/full/28_imogie.htm

Inem V, Kanu R, Atere AA (2008). Baseline knowledge, practices and experiences of Traditional Birth Attendant (TBAs) on HIVAIDS before commencement of training for prevention of mother to child transmission of HIV (PMTCT) in South west Nigeria. Nigerian Medical Pract. 53(6):103-109.

Itina SM (1997). Characteristics of traditional birth attendants and their belief and practices in the Ofot clan, Nigeria. Bull World Health Organ 75(6):537-538

Jemal Y, Tedla M, Tilahun N, Dawit S (2010). Revisiting the exclusion of traditional birth attendants from formal health systems in Ethiopia. AMREF Discussion Paper Series, 3 Discussion Paper No. 003/2010.

Jokhio AH, Winter HR, Chieng KK (2005). An intervention involving traditional birth attendants and perinatal and mortality in Pakistan. $\mathrm{N}$. Engl. J. Med. 352(20):2091-2099. 
Khan KS, Wojdyla D, Say L, Gulmezoglu AM, Van Look PF (2006). WHO analysis of causes of maternal dealth: a systematic review. Lancet 367(9516):1066-1074.

Lawn JE, Cousens S, Zupan J (2005). 4 million neonatal death when? Why?. Lancet 365(9464):891 - 900.

Martey JO, Djan JO, Twum S, Browne ENI Opuku SA (1998). Referrals for Obstetrical Complications from Ejisu District, Ghana. West Afr. J. Med. 17(2):58-63.

Martines J, Paul VK, Bhutta ZA, Koblinsky M, Soucat A, Walker N, Bahl R, Fogstad H, Costello A (2005). Neonatal survival. A call for action. Lancet 365(9465):1189-1197.

Nwakwuo GC, Oshonwoh FE (2013). Assessment of the Level of Male Involvement in Safe Motherhood inSouthern Nigeria. J. Community Health 38(2):349-356. DOI 10.1007/s10900-012-9620-6.

Okafor CB, Rizzuto RR (1994). Women and health care provider views of maternal practices and services in rural Nigeria. Study of family planning 25 (6pt 1):1994; 353-361.

Owigar RA (2000) Traditional Birth Attendants (TBAs): An Alternative Health. Resources in the Book of Abstract, Gender and Science and Technology (GASAT) $29^{\text {th }}$ October $-3^{\text {rd }}$ November, 2000; 50.

Ray AM, Salihu HM (2004). The impact of maternal mortality interventions using traditional birth attendants and village midwives. J. Obstet. Gynaecol. 24(1):5-11.

Ronsmans C, Graham WJ (2006). Maternal mortality: who, when where and why. Lancet 368(9542):1189-1200.

Sibley Lynn M, Sipe (2006). Theresa Ann. Transition to skilled birth Attendance: is there a Future Role for Trained Traditional Birth Attendants? J. Health Popul Nutr. 24(4):472-478.
Stock R (1983). Distance and the Utilization of Health facilities in rural Nigeria. Soc. Sci. Med. 17 (19):563-570.

Tsui AO, Wasserheit JN, Haaga JG (1996). Editors. Reproductive Health in Developing Countries: Expanding Dimensions, Building Solutions. Washington DC.

United Nations Children's Fund (2001). Children's and women's rights in Nigeria: a wakeup call. Situation Assessment and Analysis. National Planning Commission Abuja and UNICEF, Nigeria, 12-15.

World Health Organization (WHO) (1999). A Joint WHO/UNFPA/UNICEF World Bank Statement. WHO Library Cataloguing-in-Publication Data, 99 / 12419 / Strategic /PCL-10000. Geneva, Switzerland.

WHO (2004a). Making pregnancy safer. The critical role of the skilled attendant: a joint statement by WHO International Capital Management (ICM) and International Federation of Gynaecology and Obstetrics (FIGO); Geneva, Switzerland.

WHO (2004b). Global Action for Skilled Attendants for Pregnant Women. Geneva. World Health Organization (WHO) (2005). World Health Report 2005: Make Every Mother and Child Count. Geneva.

World Bank (2003). Reducing maternal mortality, learning from Bolivia, China, Egypt, Honduras, Indonesia, Jamaica and Sri Lanka. Human Development Network, Health Nutrition and Population Series. The World Bank, Washington DC, 2003. 